\title{
Senna Fruit
}

National Cancer Institute

\section{Source}

National Cancer Institute. Senna Fruit. NCI Thesaurus. Code C29447.

The fruit of Cassia acutifolia and Cassia angustifolia (Cassia) with laxative and purgative activities. The active ing redients in senna fruit include the hydroxyanthracene glycosides sennosides $A$ and $B$ (rhein dianthrones) and sennosides $C$ and $D$ (rhein aloe-emodin heterodianthrones). Sennosides irritate the bowel lining and stimulate the bowel muscular coat, particularly in the colon, resulting in accelerated bowel transit and evacuation. 